\title{
ENCARCERAMENTO EM MASSA, RACKETEERING DE ESTADO E RACIONALIDADE NEOLIBERAL
}

Laurindo Dias Minhoto é Professor do Departamento de Sociologia da Universidade de São Paulo (USP).

São Paulo, SP, Brasil.E-mail: Idm@usp.br

Orcid: 0000-0001-6388-9669

http://dx.doi.org/10.1590/0102-161191/109

Se é certo que a análise do caráter a um tempo estruturado e estruturante dos regimes punitivos tem se apresentado como instância privilegiada de observação da sociedade, hoje, essa dimensão por assim dizer cognitiva da punição enfrenta o desafio da compreensão de um amplo conjunto de transformações que, neste início de milênio, vem redefinindo o sentido, a natureza e o funcionamento não só da prisão, mas do sistema de justiça criminal (SJC) de diversos países tanto ao norte como ao sul do capitalismo global.

"Regressão penal” (Radzinowicz, 1999), "justiça atuarial” (Simon, 2013), "guinada punitiva”, "crise do welfarismo penal”, "cultura do controle" (Garland, 2001a), "punição da pobreza" (Wacquant, 2010), "sintomas descivilizadores" (Pratt, 2011), "governo pelo crime" (Simon, 2007) e "contrainsurgência” (Harcourt, 2018) constituem algumas das expressões com que a literatura especializada no campo da sociologia da punição tem procurado dar conta, cada autor a seu modo, de diferentes aspectos desse vasto conjunto de mudanças que repõe a prisão no centro das estratégias de controle penal, imprime um sentido punitivo às chamadas penas comunitárias, abre o SJC tanto aos interesses 
econômicos quanto aos cálculos imediatos das disputas político-eleitorais e alça a perspectiva da vítima ao centro das representações sociais do crime e do castigo.

Subjacente a muitas dessas interpretações está a discussão sobre a reforma do Estado contemporâneo, com ênfases analíticas variadas, seja na contração das políticas sociais e na expansão correspondente das políticas penais (Wacquant, 2010), seja na ruptura do monopólio do uso legítimo da força e na crescente tendência à despacificação do território (Pratt, 2011), ou ainda na emergência de estratégias de controle do crime que estendem o campo para além dos limites do Estado nacional (Garland, 2001a). ${ }^{1}$

É exatamente no interior desse quadro mais abrangente de reforma do Estado e das políticas penais que emergem novas estratégias de controle do crime, como o controle situacional do crime e a política de tolerância zero, e tendências estruturais de mudança no funcionamento do SJC de vários países, como o encarceramento em massa e a militarização do controle penal. ${ }^{2}$

\footnotetext{
${ }^{1}$ Em termos comparativos, note-se, no entanto, que essas tendências gerais de mudança não assinalam a homogeneização das práticas de controle, na medida em que a natureza da reforma do Estado, o desenho de arranjos institucionais e o funcionamento do SJC se combinam de modos distintos em diferentes contextos sociais, marcados por trajetórias históricas específicas de controle social. O que se quer sublinhar aqui é que essas tendências gerais têm estruturado a mudança de muitos SJC e, não por acaso, a correlação entre orientação neoliberal de reforma do Estado e graus mais elevados de punição e encarceramento em muitos países é bastante expressiva (Cavadino e Dignan, 2007).

2 Neste artigo, a ênfase recai sobre o encarceramento em massa; a militarização contemporânea do controle penal diz respeito à extensão de saberes e práticas militares ao controle do crime e de condutas consideradas de risco em muitas cidades do capitalismo global. O caso norte-americano é emblemático. Na esteira da guerra ao terror e da nova política anti-imigração, milhares de distritos policiais têm sido equipados com equipamentos militares, originariamente pensados como apoio à construção de redes de inteligência antiterrorista, que vêm sendo crescentemente utilizados para operações policiais rotineiras e controle de protestos políticos, como os do movimento Occupy Wall Street. Em relação à política antidrogas, nota-se o redirecionamento das operações da SWAT (Special Weapons and Tactics), equipes de operações táticas e armas especiais, principais consumidoras de armamentos militares, que, implementadas na esteira das revoltas políticas dos anos 1960, cada vez mais têm atuado no "combate" ao tráfico e uso de entorpecentes, executando mandados de prisão, monitorando transações e realizando o patrulhamento ostensivo de zonas de alta criminalidade (Balko, 2013; Vitale, 2014).
} 
Dessa perspectiva, postula-se que (i) o encarceramento em massa constitui uma espécie de ponta-de-lança da mudança penal contemporânea, permitindo jogar luz sobre certos traços que marcam a direção, o alcance e o sentido dessa mudança em diferentes contextos sociais; (ii) a reforma do Estado, vista pelo prisma analítico entreaberto por esse processo e o modo como ela se conecta ao funcionamento do SJC, pode ser compreendida como resultado de uma recomposição abrangente entre diferentes tecnologias de poder, esferas e estruturas sociais; (iii) a observação desses processos no contexto brasileiro parece indicar a possibilidade de distinguir tanto o caráter articulado dessas tecnologias de poder quanto certos traços definidores da direção mais geral assumida por esses cruzamentos.

Com base nesses postulados, o que segue é uma tentativa de (i) elaborar teoricamente a articulação truncada entre gestão autoritária do crime e da violência e gestão eficiente de organizações às voltas com o problema da lei e da ordem; (ii) flagrar nessa articulação entre autoritarismo e eficiência uma das figuras decisivas da racionalidade neoliberal e alguns de seus impactos no SJC tanto ao norte como ao sul do capitalismo global; (iii) indicar certos aspectos da experiência brasileira de controle do crime e da violência como instrumentos heurísticos para a própria especificação desse conceito de racionalidade neoliberal.

Para tanto, o artigo prossegue pela (i) apresentação de um quadro analítico para pensar a natureza híbrida e contraditória dos regimes punitivos contemporâneos que enfatiza o caráter articulado de tecnologias de poder, sistemas e estruturas sociais; (ii) análise crítica de parte da literatura hegemônica sobre encarceramento em massa que frequentemente mobiliza dicotomias conceituais e apresenta rupturas de época demasiado rígidas e estanques; (iii) consideração de aspectos da experiência brasileira de controle penal como reveladores dos modos pelos quais a disseminação de uma grade econômica de 
inteligibilidade por diferentes esferas da vida e a busca por eficiência que lhe é correlata não ocorrem sem o apelo reiterado a mecanismos autoritários de controle e imposição de condutas - neste passo, a mediação teórica e conceitual é buscada nas dinâmicas de criação e reprodução de mercados ilegais e informais no país, na forma como elas andam de par com a adoção de práticas análogas às dos rackets e na apropriação violenta de recursos econômicos e meios de poder; (iv) apresentação e leitura do caso Ferguson como expressão emblemática de neoliberalização e periferização de agências de controle no norte global, processos percebidos pelo ângulo do amálgama entre autoritarismo e eficiência que tem marcado a história do controle penal na sociedade brasileira.

\section{Três engates estruturais}

Para pensar a punição e os nexos que hoje a vinculam de forma renovada à sociedade, em particular a prisão e as 164 mudanças que redefinem seu lugar no SJC e nas estratégias de controle social, propõe-se um quadro analítico que articula três "engates estruturais" entre diferentes tecnologias de poder, sistemas e estruturas sociais. O objetivo é possibilitar o mapeamento da lógica securitária mais geral que se expressa no encarceramento em massa e na militarização do controle do crime e indicar o modo como ela é cimentada pela emergência de uma racionalidade política neoliberal.

De um lado, trata-se de considerar possibilidades de articulação entre soberania, disciplina e governo das populações e o modo como o funcionamento dos sistemas penitenciários expandidos expressa, ao mesmo tempo, a forma dessa articulação e contribui para constituí-la. Dessa perspectiva, a ênfase da análise recai não na substituição de uma determinada tecnologia de poder por outra, mas na forma específica da sua articulação em diferentes contextos sociais. $\mathrm{O}$ desafio estaria em pensar eventuais deslocamentos das tecnologias de poder e a forma de sua combinação (Collier, 2011). Ou ainda, 
em repensar o lugar tanto da soberania quanto da disciplina "no interior das formas governamentais contemporâneas" (Dean, 2010, p. 36). Se a prisão, como "máquina disciplinar", parece em crise por causa da reforma das políticas de reabilitação e das mudanças no mercado de trabalho, a disciplina, em contrapartida, permanece decisiva para a tendência de controle crescente de condutas (em especial as "de rua"); nota-se também o acionamento intensificado de medidas soberanas de exceção que frequentemente acompanham as estratégias de administração punitiva da pobreza (Beckett e Herbert, 2010; Wacquant, 2010). Como se sabe, controle de condutas e medidas de exceção constituem dois dos principais vetores do encarceramento em massa e da militarização do controle do crime.

De outro, trata-se de investigar como se articulam economia, direito e política no modo de operação do SJC. Dizendo de outra maneira, e para falar nos termos da tradição de teoria dos sistemas, importa pensar a forma e a direção pelas quais as diferentes racionalidades que recortam o SJC se compõem atualmente. Para ficarmos com a análise bem conhecida de David Garland (2001a) sobre a cisão verificada no SJC de países anglo-saxões entre as estratégias de combate ao crime que se apoiam na "criminologia do outro" e as que se apoiam na "criminologia de si", poder-se-ia verificar nessas duas tendências uma crescente colonização política do SJC - na linha do populismo penal - e também uma crescente colonização econômica do SJC - na linha da mercantilização das polícias e das prisões. Dessa perspectiva, a emergência da racionalidade política neoliberal permitiria identificar eventuais dinâmicas desdiferenciadoras entre os sistemas jurídico, político e econômico, com impacto significativo sobre o funcionamento do SJC. ${ }^{3}$

Em um terceiro nível analítico, trata-se de ver como se articulam estratégias de controle do crime e gestão da violência em estruturas sociais crescentemente polarizadas. Cumpre

3 Para uma proposta teórica de análise dos efeitos corrosivos do neoliberalismo sobre a autonomia de distintos sistemas sociais, ver Minhoto (2017). 
refletir aqui sobre o impacto que o aumento expressivo das desigualdades sociais em certos países do capitalismo global, bem como eventuais "efeitos bumerangue" (Foucault, 2003) e trocas de tecnologia de controle entre norte e sul exercem sobre o funcionamento do SJC. O desafio estaria em pensar os transplantes de tecnologias de controle (policiamento de "tolerância zero", prevenção situacional do crime etc.) como indicativos, ao mesmo tempo, de uma espécie de "periferização" do controle no centro e de reposição de padrões autoritários de controle na periferia - que não por acaso figura como grande laboratório de testes de muitas dessas tecnologias (Graham, 2012; Minhoto, 2015; Wacquant, 2007). No caso brasileiro, em especial, trata-se de examinar as possibilidades que se abrem para a reativação, em novas bases, de certos traços definidores do padrão autoritário de controle penal no país. ${ }^{4}$

Esse quadro servirá de orientação à identificação de possibilidades e limites analíticos presentes em parte da literatura hegemônica da sociologia contemporânea da punição sobre o encarceramento em massa. Noutros termos, discutem-se a seguir aspectos dessas análises, produzidas no contexto dos países centrais, pelo filtro de um certo tipo de reflexão sobre a experiência brasileira de controle penal, que enfatiza a questão dos engates entre distintas tecnologias de poder e entre esferas e estruturas sociais.

\footnotetext{
4 No âmbito da sociologia da punição latino-americana, Sozzo vem desenvolvendo uma proposta instigante de análise das trocas desiguais de controle penal entre centro e periferia; com base na noção de tradução como "conversação cultural", em que se verificam "criatividade e inovação" nos dois polos, o autor propõe avançar em relação ao nexo estabelecido pela criminologia crítica dos anos 1970 entre dependência econômica periférica e hegemonia de formas jurídico-penais do centro (2001, pp. 417 e ss.) Aqui não se trata de rechaçar em abstrato essa importância da cultura sublinhada pelo autor, mas, antes, indicar que o fluxo desigual de importação de formas jurídicas entre norte e sul não só persiste como parece assinalar, atualmente, o paradoxo do reforço de certos traços que sempre caracterizaram o contexto de práticas de controle penal no sul, que assim importa e consome práticas punitivas análogas às que historicamente lhe são constitutivas. Em textos mais recentes, e em linha analítica oposta à deste artigo, o autor vê na emergência de governos de centro-esquerda na América Latina das primeiras décadas do século XXI uma relativização do nexo entre encarceramento em massa e diagnósticos centrais de neoliberalização do SJC (Sozzo, 2014, 2016).
} 


\section{Análises hegemônicas do encarceramento em massa}

Nos termos da conhecida formulação de D. Garland, o encarceramento em massa se caracteriza, em primeiro lugar, pelos fatos brutos da abrangência da população prisional e da magnitude da taxa de encarceramento; em segundo lugar, pode-se dizer que o encarceramento se torna encarceramento em massa quando deixa de funcionar como mecanismo de aprisionamento do indivíduo transgressor e passa a operar como mecanismo de aprisionamento de estratos populacionais. Atualmente, na democracia liberal norte-americana, "a prisão deixa de constituir o destino de uns poucos criminosos para tornar-se a instituição modeladora de vastas parcelas da população" (Garland, 2001b, p. 3).

Segundo inúmeras pesquisas, alguns dos principais efeitos do encarceramento em massa são: o agravamento do déficit público; a realocação progressiva do fundo público da área social (saúde, educação, habitação) para o sistema de justiça criminal; a rotinização da experiência prisional e a centralidade dessa experiência na organização da vida em distintas comunidades; o efeito criminogênico do cárcere, tendo em vista as altas taxas de reincidência a ele associadas; a destituição do direito de voto de parcelas significativas da população; o reforço e agravamento das divisões sociais tendo em vista o viés de classe, gênero e étnico-racial das práticas punitivas, constelação de que faz parte a elaboração ideológica da underclass (Garland, 2001a; Simon, 2013; Wacquant, 2010). ${ }^{5}$

As altas taxas de encarceramento que se verificam hoje em países do norte e do sul, como EUA e Brasil, países que se encontram no topo dessa peculiar "corrida carcerária",

\footnotetext{
${ }^{5}$ O caráter enviesado da expansão da rede de controle penal se expressa na crescente sobrerrepresentação de pobres, negros, mulheres e migrantes na população penitenciária. No contexto norte-americano, verifica-se, ao longo das últimas décadas, não só a crescente correlação negativa entre taxa de encarceramento e benefícios sociais providos por diferentes estados da Federação, como também se estreitam as correlações positivas entre taxa de encarceramento e participação de negros e grupos minoritários na composição da população prisional (Beckett e Western, 2001).
} 
parecem estreitamente relacionadas à adoção de novas estratégias de controle do crime. A regulação e o monitoramento de condutas tidas como indesejáveis em vias públicas, parques, complexos comerciais, espaços residenciais e outros equipamentos públicos responde, em grande medida, pela disseminação da prática do encarceramento de curta duração, pelo alto grau de rotatividade de parte da população penitenciária ("prende e solta”), pelo crescimento no número de prisões provisórias e pela extensão seletiva da rede de controle penal.

Dessa perspectiva, se é certo que o encarceramento em massa se relaciona à adoção de leis mais severas no campo do controle penal, em especial a reboque da política de guerra às drogas, da qual a famigerada "three strikes and you are out" constitui emblema, bem como à introdução de sentenças mandatórias e determinadas que limitam a discricionariedade dos juízes na análise de casos concretos, sempre na direção do aumento do uso da prisão e dos termos de 168 duração da pena, além da erosão de garantias processuais, pode-se verificar uma vinculação crescente entre essas inovações legislativas e judiciais e o governo dos espaços urbanos. ${ }^{6}$

Na produção do encarceramento em massa muitas das novas estratégias de controle da conduta encontram na gestão dos espaços urbanos justamente as condições para a ativação de uma lógica de securitização de espaços que se põe cada vez mais em termos de monitoramento de riscos, policialização de condutas e eficiência sistêmica. A tentativa de compreender essa lógica securitária de gestão de riscos constitui uma das principais tendências analíticas da sociologia da punição.

Nos termos da conhecida análise de Jonathan Simon (Feeley e Simon, 1992; Simon, 2007, 2013), o andamento de muitos SJC tem sido marcado pela emergência de uma nova penologia, a "justiça atuarial", em que a ênfase tradicional

\footnotetext{
6 Para uma discussão sobre governo dos espaços urbanos e racionalidade neoliberal, ver Minhoto (2014; 2015).
} 
do direito e da criminologia no indivíduo tende a ser substituída por uma ênfase crescente na consideração atuarial de agregados populacionais, deslocando o processo criminal na direção do uso intensificado da prisão, do amálgama vigilância e custódia e do monitoramento de grupos considerados perigosos (Feeley e Simon, 1992, p. 449). Nesse deslocamento, o discurso do risco e da probabilidade tende a substituir o discurso disciplinar do diagnóstico clínico e o discurso jurídico da retribuição; objetivos voltados à gestão eficiente de processos sistêmicos internos tomam o lugar dos objetivos tradicionais de controle do crime e reabilitação e, decisivamente, "a linguagem atuarial do cálculo probabilístico e das distribuições estatísticas é aplicada à população" (Feeley e Simon, 1992, p. 452).

Portanto, segundo essa vertente da sociologia da punição, na démarche da governamentalização da ponta penal do Estado, as operações do SJC tendem a se deslocar cada vez mais do controle do crime em sentido estrito para o controle das condutas de agregados populacionais: "não se trata mais de punir ou reabilitar indivíduos, mas de identificar e gerir grupos 'desgovernados'; o objetivo não é eliminar o crime, mas torná-lo tolerável por coordenação sistêmica” (Feeley e Simon, 1992, p. 452). ${ }^{7}$

A esse respeito, note-se que o primado da incapacitação prisional parece encontrar um dos seus móveis justamente nessas reorientações do sistema que prometem reduzir os efeitos do crime na sociedade, não por estratégias de intervenção no ofensor, nem tampouco no contexto social, mas pelo rearranjo da distribuição dos ofensores na sociedade, com emprego de esquemas distintos de controle e vigilância

\footnotetext{
7 A lógica securitária subjacente a esse processo de governamentalização do SJC se deixa entrever na requalificação do sentido das taxas de reincidência: se num momento histórico anterior, normativamente carregado pelo ideal de reabilitação, altas taxas de reincidência constituíam índice de falha sistêmica, hoje elas tendem a ser vistas como índice de eficiência, redefinindo a natureza do parole board como mecanismo de controle e reforçando a centralidade da prisão no campo das novas políticas penais.
} 
do ambiente, tendo em vista o monitoramento de grupos considerados mais ou menos perigosos. Não por acaso, a chamada incapacitação seletiva tem sido proposta como um mecanismo de sentenciamento em que a duração da pena depende cada vez menos da natureza do crime praticado ou da avaliação do caráter do criminoso e cada vez mais da elaboração de perfis de risco que possibilitem seu controle a longo prazo dentro e fora das prisões. ${ }^{8}$

Nesse processo, fica em segundo plano a reflexão sobre o papel que condições sociais desagregadoras podem desempenhar na produção do crime e do criminoso. O que antes aparecia para o sistema de justiça criminal como eventual limite de sua atuação e como zona de intervenção governamental, agora surge como zona privilegiada de gestão do risco pelo que implica em termos de potencial ameaça à segurança dos consumidores de justiça. ${ }^{9}$

Ao buscar prover segurança a cidadãos concebidos como 170 consumidores de serviços de justiça, com base na elaboração de perfis de risco de agregados populacionais e na regulamentação e policialização de condutas consideradas indesejáveis, a lógica securitária subjacente às novas estratégias de controle que estão na raiz do encarceramento em massa tende a operar um baralhamento crescente das fronteiras entre crime e condutas indesejáveis. Migrantes, mendigos, grafiteiros, skatistas, drogaditos e outros alvos privilegiados da atuação policial fazem ver que a "desordem se converte em gradiente do crime - quebrar janelas, jogar lixo nas ruas, pular uma catraca constituem graduações de um espectro que no limite se estende ao homicídio" (Harcourt, 2001, p. 149).

\footnotetext{
8 Em relação às políticas antidrogas, tão decisivas para a emergência do encarceramento em massa, nota-se também um deslocamento de ênfase do tratamento para a cultura dos testes e da avaliação, de modo que o uso de droga passa a ser percebido como indicador de risco, ou seja, não como uma prática desviante individual, mas como mecanismo de classificação de ofensores em grupos de risco.
}

9 Para uma discussão sobre neoliberalismo penal, risco e consumo, ver O'Malley (2009). 
De um outro ponto de vista, para além de uma guinada atuarial, o encarceramento em massa seria sintoma, antes, de um giro pós-moderno no funcionamento do SJC, impulsionado por uma cultura de "excesso punitivo", podendo assinalar uma ruptura gradual com o processo de racionalização das práticas punitivas modernas. Num contexto de guerra ao crime e de vingança judicial, o uso da prisão seria reconfigurado como critério de legitimação de performance do sistema de justiça criminal: "não se trata mais de reduzir a população prisional, mas de ampliá-la o máximo possível [...] ferir e fazer sofrer os detentos constitui agora índice de vitalidade do direito" (Hallsworth, 2002, p. 156); iria também nessa direção a disseminação de práticas punitivas arbitrárias, que tendem a pôr em xeque a busca de proporcionalidade entre crime e castigo, na linha do dispositivo legal three strikes and you're out. Dessa perspectiva, a prisão pós-reabilitativa, de que as supermax norte-americanas seriam paradigma, põe às claras os limites do ethos correcionalista típico do pós-guerra, assim como as práticas panopticistas que lhe seriam correlatas (Hallsworth, 2002).

Para uma outra análise hegemônica no campo, o encarceramento em massa associa-se a um processo mais geral de enraizamento de uma "cultura do controle" no SJC (David Garland, 2001a), com andamento bifurcado: numa ponta, mais próxima do quadro técnico encarregado da operação do sistema, nota-se a absorção de certa racionalidade econômica voltada ao corte de custos e à gestão eficiente da performance do sistema, à aferição de riscos e ao controle, no ambiente, das oportunidades para a prática de delitos (aqui, a intermediação entre a percepção social nas ruas e o SJC é feita pela "criminologia de si"); na outra ponta, mais próxima do quadro político do sistema, encarregado da formulação da política penal, verifica-se uma espécie de reação negativa ou de bloqueio (acting out) diante da suposta fragilidade do Estado no controle do crime, reafirmando-se, 
em chave autoritária, sua soberania, o que se traduz frequentemente na corrida progressiva pelo aumento de penas, na criminalização de condutas e na demonização do criminoso, visto em termos marciais como inimigo a ser abatido (aqui, a intermediação é feita pela "criminologia do outro"). De tal forma que o SJC que se vai reconfigurando na esteira da crise do welfarismo penal assume feição esquizoide.

Já para o autor da conhecida tese da punição da pobreza (Wacquant, 2010), o encarceramento em massa deve ser analisado no registro interpretativo da crise do Estado social e da emergência de um Estado bifronte, um centauro dócil e flexível da cintura para cima (em relação aos donos do poder e do dinheiro) e autoritário e patriarcal da cintura para baixo (tanto na ponta social, quanto na ponta penal, o que expressaria um movimento de crescente convergência institucional). Aqui o Estado é gestor, em chave punitiva, da insegurança social que ele mesmo auxilia a instaurar na 172 passagem do arranjo regulatório forjado pelo compromisso keynesiano e pela social-democracia (ou do arranjo regulatório do New Deal no caso do Estado semicaritativo estadunidense) para o projeto neoliberal de governo. Segundo Wacquant, "enquanto [o Estado] abraça o laissez-faire no topo, liberando restrições sobre o capital e expandindo as chances de vida dos detentores de capital econômico e cultural, [ele] é tudo menos laissez-faire embaixo" (2010, p. 214). Portanto, se o punitivismo integra a racionalidade liberal, e nesse sentido ela não se confunde com a vulgata do Estado mínimo, ao menos para o andar de cima é de laissez-faire, principalmente, que se trata o caso.

Por sua vez, os estudos de Beckett e Herbert (2008, 2010) têm iluminado a questão do encarceramento em massa a partir do ângulo da adoção de medidas jurídicas de restrição da mobilidade urbana e do uso do espaço público, tais como o retorno do banimento na execução de sentença condenatória (vedando ao apenado a circulação por zonas 
urbanas associadas ao comércio de drogas e à prostituição), a proibição de frequentar certos espaços da cidade como parques, universidades, bibliotecas, lojas, e a extensão dos mecanismos de defesa da propriedade.

Para os autores, esse processo encerra uma espécie de extensão encoberta do direito penal, já que tem ocorrido pela inobservância das garantias jurídicas próprias ao exercício do direito de defesa - especialmente as da esfera penal, em que elas são mais exigentes (Beckett e Herbert, 2010, p. 4); uma espécie de efeito perverso da maquiagem jurídica do caráter substantivamente punitivo dessas medidas, que assim operam a suspensão de direitos individuais por meio de regulamentos administrativos. A partir da análise dos autores, talvez se pudesse divisar nesses mecanismos a última geração no capítulo das medidas de exceção, que, em vez de declarar expressamente a suspensão de direitos no âmbito de uma situação especial de emergência, vai instaurando essa mesma suspensão pela via das rotinas policiais administrativas.

\section{Experiência brasileira e racionalidade neoliberal}

Risco e disciplina, crime e ordem urbana, proporcionalidade e excesso punitivo, criminologia de si e do outro, eficiência econômica e populismo penal, Estado social e Estado penal, medidas administrativas e medidas penais constituem alguns dos pares analíticos opostos mobilizados de diferentes ângulos teóricos pela sociologia hegemônica da punição para dar conta do "novo", isto é, daqueles aspectos em que o encarceramento em massa parece superar e romper com a racionalidade dos regimes punitivos que o precederam.

É justamente esse ponto de fuga, orientado pelas ideias de ruptura e de superação de regimes punitivos e paradigmas, subjacente a muitos dos diagnósticos produzidos pela sociologia da punição, que parece pôr na sombra possibilidades analíticas que valorizem não apenas as linhas de continuidade, mas, antes, os próprios modos de articulação entre 
diferentes tecnologias, esferas e estruturas sociais no encarceramento em massa. Por essa outra via, talvez se abrisse a possibilidade para matizar a própria noção de uma "guinada punitiva contemporânea", com o acento posto nos diversos cruzamentos (ou engates) que acionam e dispõem em novos termos topologias de poder, processos de colonização entre esferas e padrões de transferência de formas (mecanismos de controle) entre estruturas sociais.

Assim é que se poderia ver como a inflexão para o risco no governo de agregados populacionais não dispensa o emprego de práticas disciplinares e de soberania; que os ganhos de eficiência na mensuração da atividade de agências de controle (como a polícia, os tribunais e a prisão) não dispensam o recurso a estratégias de responsabilização individual e a um discurso de essencialização do outro; que a adoção de "gambiarras jurídicas" (Telles, 2013) para restringir a circulação de populações consideradas "poluentes" 174 do espaço urbano se articula a estratégias soberanas de gestão empresarial voltadas à valorização econômica de certas regiões da cidade (Minhoto, 2014); que o incremento da ponta penal do Estado não requer necessariamente o desmonte das estruturas do Estado social, muito menos a simples adesão ao receituário econômico do consenso de Washington, transcorrendo, antes, pelo acionamento seletivo de mecanismos securitários, disciplinares e soberanos, reorientados seja para a extensão do controle de condutas nas ruas e nos estabelecimentos prisionais, seja para a busca de novos mercados (como os da segurança e das prisões).

É precisamente dessa perspectiva que o andamento híbrido da experiência histórica das estratégias de controle penal em sociedades periféricas, como a brasileira, poderia funcionar como uma espécie de "locus de veridição" das tendências de mudança na penalidade contemporânea, na medida em que o outro da pretendida sobriedade punitiva moderna a economia punitiva de excesso e a economia punitiva atuarial - 
se articula contraditoriamente ao processo de racionalização do sistema de justiça criminal, formando uma situação contraditória em que os contrários se constituem, se limitam e se desautorizam reciprocamente (Minhoto, 2011).

Em termos históricos, como já indiquei em outra oportunidade (Minhoto, 2015), a gestão do complexo capitalista-escravocrata no Brasil requereu, no marco de um projeto de construção nacional socialmente excludente e de modernização pelo alto, a montagem de uma maquinaria institucional de controle preventivo e repressivo de condutas das classes desprivilegiadas, operando como suporte das distinções de classe e raça que importavam manter na passagem da colônia à nação independente. Em certo sentido, a formação das polícias no Brasil significou a transferência e a extensão das tecnologias de poder mobilizadas pelo senhor no controle dos escravos para os homens livres e pobres circulando pelas cidades em rota de urbanização acelerada. Por aí se pode ver algo como a constituição de um aparato repressivo de Estado no espelho da gestão soberana, disciplinar e privada das classes subalternas.

Se é, pois, de articulação que se trata o caso, e não propriamente de superação, o decisivo é saber a direção geral dessas articulações. Salvo engano, essa direção é dada cada vez mais pela emergência e disseminação de uma racionalidade neoliberal que se espraia por distintos âmbitos da sociedade. Em outras palavras, atravessando os engates entre topologias de poder, esferas e estruturas sociais, essa racionalidade imprime direção a esses processos e adquire configuração específica ao orientar as atividades de agências estatais e não estatais de controle.

O ponto a ser sublinhado, portanto, é que a experiência periférica e, em especial, a brasileira, poderia se constituir em plataforma privilegiada de observação não apenas do caráter híbrido das tecnologias de poder que se configuram na produção do encarceramento em massa e dos efeitos bumerangue 
que mais e mais aproximam padrões de controle da conduta no centro e na periferia do capitalismo global, mas sobretudo da própria direção mais geral assumida por esses processos.

Dizendo de outro modo, trata-se de levar a sério a observação segundo a qual uma "tecnologia de poder pode proporcionar normas diretoras e um telos orientador. Mas ela não satura todas as relações de poder. Ela sugere antes um princípio de configuração que determina como elementos heterogêneos [...] são reunidos e determinados (Collier, 2011, p. 261). E aqui "o mais importante" é atentar para "uma série de edifícios complexos nos quais [...] o que muda é, acima de tudo, a característica dominante, ou mais exatamente, o sistema de correlação entre mecanismos jurídicos-legais, mecanismos disciplinares e mecanismos de segurança” (Foucault, 2007, pp. 6-7).

É na esteira desse "achado" da analítica do poder que a experiência brasileira é proposta como revelador heurístico

176 de certos contornos frequentemente insuspeitados que a noção de racionalidade neoliberal pode assumir; uma racionalidade que aqui se toma, justamente, como "princípio de configuração" ou "sistema de correlação" que determina a direção assumida por uma dada topologia de poder. E é à luz dessa mesma experiência brasileira, portanto, que se trata de sublinhar como a disseminação de uma grade econômica de inteligibilidade por diferentes esferas da vida e a busca por eficiência que lhe é correlata não ocorrem sem o apelo reiterado a mecanismos autoritários de controle e imposição de condutas.

\section{Mercadoria política e racketeering}

Considera-se que a articulação neoliberal entre autoritarismo e eficiência talvez se deixe entrever de modo mais nítido nos processos de criação e reprodução de mercados ilegais e informais no país, em que a extração de recursos econômicos e a adoção de mecanismos de incremento e controle de 
performance andam de par com a apropriação violenta de recursos e meios de poder. Nesse sentido, as conhecidas reflexões de Michel Misse (2007, 2008, 2018) sobre a reconfiguração dos mercados ilegais e informais no país, em especial no Rio de Janeiro, na esteira do processo de "acumulação social da violência" e do recurso reiterado às mercadorias políticas como forma privilegiada de garantir o funcionamento desses mercados, poderiam ser mobilizadas como contribuições decisivas para clarificar o conceito de racionalidade neoliberal.

Ao discutir a emergência de organizações criminosas voltadas aos mercados de tráfico de drogas e de armas, Misse nos faz ver como o papel desempenhado pela polícia combina política de extermínio, negociação de proteção e busca de eficiência operacional: "A polícia veio crescentemente a adotar uma política de extermínio, oferecendo bônus aos oficiais por prisões ou execuções de chefes do tráfico [...] Ao mesmo tempo que captura e mata, a polícia negocia proteção aos traficantes" (2018, p. 140). É nessa imbricação que o autor flagra a disseminação crescente do jogo das mercadorias políticas na gestão dos mercados ilegais. Como se sabe, uma mercadoria política é aquela produzida num contexto de troca assimétrica, "quase sempre compulsória, ainda que a sua realização seja geralmente do interesse de ambas as partes. $\mathrm{O}$ seu preço depende simultaneamente de um cálculo político e econômico” (Misse, 2018, p. 143).

Com apoio em Weber, Misse nota ainda que o capitalismo de rapina ou político, aquele que opera pela apropriação direta e violenta de recursos, não corresponde meramente a um passado pré-capitalista, mas persiste e se estende, ainda que sempre em tensão com a compreensão moderna de um mercado orientado pela livre concorrência e regulado pelo direito racional. Nessa linha ele afirma decisivamente que "os ganhos nesse mercado não resultam exclusivamente da lei da oferta e da demanda, mas de uma relação de força, uma relação de poder" (Misse, 2018, p. 144). 
Se assim é, "não seria possível compreender a reprodução das organizações criminosas de todos os tipos sem fazer referência ao fato de que elas produzem ou estão submetidas à mercadoria política” (Misse, 2018, p. 144).

Do ângulo que mais nos interessa ressaltar aqui, essa situação não indicaria tanto a permanência complementar de práticas violentas de apropriação ao lado de práticas competitivas de livre mercado (Misse, 2018, p. 144), quanto a possibilidade de conceber, na sua crescente articulação, novos contornos da racionalidade neoliberal. Antes de tudo, importaria notar que essa racionalidade não é mera portadora, sem mais, dos princípios da livre concorrência no mercado, da competição e da soberania do consumidor e da figura da empresa - a serem disseminados pelas mais diferentes esferas da sociedade -, mas, antes, parece constituir uma nova forma de dominação em que estratégias securi178 tárias, disciplinares e soberanas se combinam e em que a competição não dispensa o recurso à apropriação direta e coercitiva de meios de produção, distribuição e circulação.

Trata-se a rigor de um jogo em que prevalece menos a ideia de livre concorrência e mais a luta por posições estratégicas de domínio, tal como o jogo travado pelas grandes corporações que operam em mercados globalizados. ${ }^{10}$ Nessa chave de interpretação, o acionamento reiterado de práticas coercitivas seria constitutivo à razão neoliberal na medida em que a formação e consolidação de novos mercados depende cada vez mais, não de uma situação de igualdade entre os diferentes jogadores dada pela livre concorrência, mas de estratégias formais e informais, mais ou menos escusas, de constituição de posições de domínio e manutenção das posições ocupadas pelos vencedores. 10 Para uma análise das tensões entre neoliberalismo e o jogo da livre concorrên-
cia no mercado, ver Crouch (2011). 
Noutras palavras, um jogo cada vez mais permeado pela troca de mercadorias políticas, tanto no andar de cima, quanto no andar de baixo da estrutura social, tanto nos mercados informais e ilegais, quanto nos mercados formais. E não por acaso é justamente nesse contexto que se assiste, tanto ao norte e quanto ao sul, à reemergência e à intensificação de diversos esquemas de racketeering, em que a componente política do jogo econômico neoliberal vem para o primeiro plano.

Em 1943, por ocasião da elaboração dos ensaios que integrariam a Dialética do esclarecimento (em coautoria com Adorno), Max Horkheimer esboçou, em texto que acabou ficando de fora do livro, os rudimentos de uma teoria do racket como ângulo privilegiado para pensar a reconfiguração das classes sociais no capitalismo oligopolista. ${ }^{11}$ Nesse trabalho, o autor relaciona a disseminação de práticas de achaque e proteção, análogas às adotadas pelas máfias e gangues da Chicago nos anos 1930, e que emprestaram relevância ao termo racket, à tendência de concentração e centralização do capital:

O conceito de racket refere-se à luta de unidades grandes e pequenas pela apropriação da maior parcela possível de mais-valia, compreendendo os mais diversos grupos, do potentado capitalista ao pequeno grupo de pressão, trabalhando dentro ou fora da lei, junto aos estratos mais miseráveis da população. (Horkheimer, 2016, p. 20)

Assim é que a abolição paulatina do princípio estrito da livre concorrência possibilita à sociedade "reverter a formas mais diretas de dominação, que de fato nunca foram completamente suspensas". Nas novas condições, "a abolição do mercado como regulador da produção constitui sintoma da influência

11 Para um debate sobre esse esboço de teoria, ver "Max Horkheimer and the sociology of class relations", número especial da revista eletrônica Nonsite de 2016, que inclui a íntegra do ensaio do filósofo alemão; entre nós, uma cuidadosa discussão sobre a teoria dos rackets encontra-se em Regatieri (2015). 
decrescente de tudo aquilo que estiver fora do âmbito de ação dos grupos decisivos" (Horkheimer, 2016, p. 18).

Ainda segundo Horkheimer, uma teoria do racket poderia auxiliar a compreender que esse "padrão de relação de classe torna-se típico não só para as relações dos grandes grupos da sociedade, mas penetra, a partir daí, todas as relações humanas, mesmo aquelas internas ao proletariado" (Horkheimer, 2016, p. 18, grifo nosso). É por isso que, acoplado ao processo de "crescente absolutismo do sistema de lucro", as práticas de racketeering terminariam por engolfar os próprios sindicatos de trabalhadores. Como se pode notar, nos termos dessa análise, a direção do movimento de difusão de práticas de racketeering tende a se dar de cima para baixo, dos grandes para os pequenos grupos. Nesse sentido, "sob um certo ângulo, a Racket-Theorie pode ser encarada como uma teoria sobre a prática política das classes dominantes, como uma teoria das elites" (Regatieri, 2015, p. 82).

Do ponto de vista da tentativa de especificar o conceito de racionalidade neoliberal, parte da tarefa estaria em mostrar como o jogo das mercadorias políticas tende a ocorrer não só no nível dos mercados ilegais e informais, mas também e cada vez mais no nível das altas finanças e da luta por posições de domínio entre global players, o que, no entanto, em muito ultrapassaria os limites deste trabalho. ${ }^{12}$

\section{Racketeering de Estado: 0 caso Ferguson}

Isto posto, e retendo certos traços definidores da dinâmica de funcionamento dos mercados informais e ilegais do país, bem como seguindo pelo atalho oferecido pela teoria do racket, vejamos como a racionalidade neoliberal - reespecificada pelo prisma da articulação truncada entre autoritarismo e eficiência presente na experiência nacional de acumulação de violência

\footnotetext{
12 Para uma análise do acionamento crescente de práticas análogas às dos rackets por parte de grandes conglomerados econômicos no capitalismo global, com ampla revisão bibliográfica, ver Granter (2017).
} 
e circulação de mercadorias políticas - poderia lançar luz sobre a natureza mais geral de aspectos do funcionamento do Estado contemporâneo e o papel que estratégias neoliberais exercem na produção do encarceramento em massa.

$\mathrm{Na}$ esteira do assassinato do jovem negro Michael Brown, em agosto de 2014, pela polícia de Ferguson, cidade norte-americana localizada no condado de Saint Louis, Estado do Missouri, e dos inúmeros protestos que se seguiram ao julgamento que decidiu pelo não indiciamento do policial suspeito de ter efetuado os seis disparos que resultaram em sua morte, o Departamento de Justiça dos Estados Unidos (doravante USDJ) produziu relatório sobre mudanças recentes nos modos de operação da polícia e da corte locais, seus efeitos sobre as estratégias de controle do crime e as relações dessas agências com a comunidade.

$\mathrm{O}$ arranjo institucional de governança em Ferguson encerra peculiaridades. A população elege o prefeito e os membros da assembleia municipal. A assembleia, por sua vez, indica o "gestor da cidade" (city manager), considerado o chefe administrativo do município. O mandato do gestor é por termo indeterminado e pode ser revogado por deliberação da assembleia. Todos os departamentos administrativos e repartições públicas estão subordinados ao gestor. O chefe de polícia é nomeado pelo gestor da cidade. O juiz da corte municipal é eleito pela assembleia municipal e nomeado pelo gestor da cidade. A corte está instalada no departamento de polícia e é supervisionada pelo chefe de polícia. O juiz preside as sessões do tribunal, mas é o "contador da corte" (court clerk) quem toca o varejo do serviço judiciário, com amplos poderes, inclusive de natureza jurisdicional, para aceitar declarações de plea guilt, expedir notificações e realizar a coleta de taxas e multas (UNITED STATES OF AMERICA, 2015, p. 8).

Entre 2010 e 2014, as agências encarregadas da aplicação da lei e da ordem em Ferguson expediram 90 mil intimações e notificações por supostas infrações ao código municipal. 
Significativamente, o número alcançado em 2014 é 50\% superior ao de 2010. Durante todo o período, as taxas de crime violento na cidade permaneceram estáveis (UNITED STATES OF AMERICA, 2015, p. 7). Nos últimos anos, a participação dos recursos gerados com a aplicação da lei e da ordem no orçamento total da cidade tem crescido substancialmente, passando de US 1,38 milhão de um orçamento de US $\$ 11,07$ milhões $(12,47 \%)$ em 2010 para US $\$ 3,09$ milhões de um orçamento estimado em US\$13,26 milhões (23,30\%) em 2015 (UNITED STATES OF AMERICA, 2015, p. 10).

Nesse contexto se põe a principal conclusão do relatório do Departamento de Justiça, a saber, que diferentes agências e autoridades municipais de Ferguson têm reiteradamente concebido e desempenhado as atividades de execução da lei e manutenção da ordem a partir do imperativo da maximização dos recursos arrecadados (UNITED STATES OF AMERICA, 2015, p. 9). Frequentemente sob a pressão de diretivas expe182 didas pelo "diretor financeiro" da cidade (finance director), braço direito do gestor, nota-se uma completa sinergia de esforços "para incrementar eficiências e maximizar a coleta" (UNITED STATES OF AMERICA, 2015, p. 10).

Dessa forma, dissemina-se entre diferentes atores do sistema de justiça uma "cultura reflexiva de aplicação da lei" (UNITED STATES OF AMERICA, 2015, p. 12), segundo a qual o imperativo da maximização de recursos se descola progressivamente do objetivo de prover segurança pública à comunidade. No âmbito dessa cultura autorreferida de "arrecadação por arrecadação", mecanismos de avaliação de performance e controle da conduta de policiais, oficiais de fiscalização de penas comunitárias e auxiliares do juiz da corte, orientados por uma racionalidade fiscalista, têm sancionado a inobservância crescente de direitos e garantias dos cidadãos.

Assim é que, no âmbito judicial, a corte vai se convertendo mais e mais em mera agência de instituição e coleta de multas, implicando a consequente usurpação da função 
jurisdicional pelo quadro de gestores, o desrespeito sistemático aos direitos dos acusados e o uso da prisão como estratégia de reforço de capacidades arrecadatórias, "sem qualquer relação com a gravidade da ofensa supostamente praticada" (UNITED STATES OF AMERICA, 2015, p. 55).

No âmbito policial, o recado das autoridades tem sido que "violações da lei e da política serão toleradas, desde que os oficiais continuem sendo 'produtivos' na realização de prisões e expedição de intimações" (UNITED STATES OF AMERICA, 2015, p. 12). Nesse cenário, não é de admirar que oficiais de polícia, crescentemente cobrados por produtividade, tenham efetuado operações de revista, busca e apreensões sem base legal, em clara afronta à quarta emenda da constituição norte-americana, que requer "causa provável" para a realização desses atos. Sublinhe-se, ainda, que a proliferação de práticas policiais e judiciais de legalidade duvidosa, para dizer o mínimo, assume inequívoco caráter racialista (UNITED STATES OF AMERICA, 2015, p. 65).

Desse ponto de vista, o "caso Ferguson" é emblemático da direção mais geral assumida por muitas práticas atuais de controle do crime e governo da conduta, incluindo a conduta de agentes encarregados da aplicação da lei e da ordem. Em contexto de austeridade fiscal, a dependência crescente de agências do sistema de justiça criminal em relação a mecanismos de extração forçada de recursos pelo incremento de taxas e multas tem se replicado em inúmeros estados norte-americanos, o que, entre outros efeitos, produz a banalização do cárcere como mecanismo trivial de coação arrecadatória.

Sem qualquer relação com a gravidade dos crimes eventualmente praticados e, portanto, em clara afronta ao princípio da proporcionalidade da sanção penal, sanções monetárias como a multa têm sido largamente utilizadas nos Estados Unidos, não como alternativa à pena de privação da liberdade, mas como suplemento fiscalista que, ao menos em parte, deve servir à manutenção das atividades das próprias agências 
encarregadas de sua aplicação. Nessa medida, as penas monetárias têm suscitado evidente conflito de interesses entre cidadão acusado e autoridades encarregadas da aplicação e execução dessas sanções (Beckett e Harris, 2011, p. 519).

Como as sanções recaem em regra sobre os setores mais desfavorecidos da população, elas tendem a produzir um efeito de "acumulação de desvantagens" pelo qual dívidas judiciais de longa duração estendem e intensificam os efeitos da sanção penal, reduzindo a renda das famílias e limitando o acesso a crédito, habitação, transporte e emprego (Harris, Evans e Beckett, 2010, p. 1791). Ainda que com óbvias limitações, o sistema de justiça criminal funcionou historicamente como importante provedor de serviços sociais aos pobres norte-americanos, em especial na "era de ouro" do correcionalismo. Estes, no entanto, hoje são crescentemente coagidos a pagar pela simples movimentação da máquina judicial, num círculo infernal em que as dívidas se avolumam de juro em juro, tornando o pagamento cada vez mais improvável e abrindo caminho, por sua vez, para o recolhimento à prisão por falta de pagamento (Harris, Evans e Beckett, 2010, p. 1792).

O decisivo aqui é a racionalidade que tende a legitimar a difusão dessas práticas, isto é, a ideia de que acusados e condenados devem ser obrigados a pagar, em sentido literal, bem entendido, pelos “custos” de autuação, defesa, julgamento e encarceramento, concebidos como "serviços" a serem remunerados pelo "usuário" da máquina judicial, e que as diferentes agências encarregadas do desempenho dessas funções podem arbitrar esses custos e fazer arrecadar diretamente os pagamentos valendo-se da chantagem da prisão como moeda de troca (Harris, Evans e Beckett, 2010, p. 1792).$^{13}$

\footnotetext{
13 O que na prática vem reabrindo o espectro do retorno da prisão por dívidas nos Estados Unidos. Se a lei veda o encarceramento de acusados pelo simples fato da sua indigência, "sem um verdadeiro processo judicial", a lei é simplesmente contornada (Western, 2017, p. 249).
} 


\section{Considerações finais}

Essa experiência de Ferguson permite dimensionar alguns dos significados que o "estar diante da lei" vem assumindo na sociedade contemporânea. Trata-se, ao mesmo tempo: (i) de oportunidades de incremento de arrecadação fiscal, das quais depende crescentemente o próprio funcionamento da máquina judicial em tempos de políticas de austeridade; (ii) de uma corrida pela extração direta de recursos por parte de agentes de aplicação da lei e da ordem pressionados por sistemas de controle de produtividade; (iii) do repasse de atribuições jurisdicionais a técnicos de agências administrativas que sobrepõem à razão jurídica dos direitos e garantias individuais uma razão eminentemente econômico-fiscalista; (iv) da circulação de um discurso de legitimação dessas práticas assentado na ideia de responsabilização individual, que articula noções econômicas como "usuário" e "serviço" e as transpõe sem mais para o universo da coação estatal; (v) de um sistema de justiça criminal que opera crescentemente descolado dos objetivos de prover segurança pública e fazer respeitar direitos de cidadania, agindo no espelho das práticas ilegais próprias de organizações criminosas, em que a prisão é reconfigurada como instrumento trivial de coação arrecadatória e moeda de troca.

Dessa forma, a generalização crescente das sanções monetárias e sua vinculação ao fenômeno do encarceramento em massa permitem verificar como, sempre sob o império da razão econômica, práticas soberanas de contorno à lei e suspensão de direitos se articulam a práticas de governo da população, que reorientam o funcionamento do sistema de justiça da aferição dos efeitos jurídicos da conduta individual para o cálculo do potencial de rendimento da gestão de condutas no agregado. Por sua vez, a parafernália disciplinar de monitoramento, avaliação e controle de condutas - tanto dos agentes do sistema quanto de acusados 
e condenados - parece se inscrever cada vez mais no interior desse mesmo cálculo. ${ }^{14}$

Segundo a conhecida análise de Judith Butler sobre o estatuto da detenção indefinida, a imbricação contemporânea entre soberania e governamentalidade se dá pela suspensão da lei ou pelo seu uso tático pelo Estado, que a instrumentaliza para fins de controle e monitoramento de uma dada população (2004, p. 55). Nos termos precisos da autora, é nessa imbricação que o Estado produz, pela sua retirada seletiva do campo do direito, "uma lei que não é lei, um tribunal que não é tribunal, um processo que não é processo" (Butler, 2004, pp. 61-62). Desse ponto de vista, e à luz do caso Ferguson, talvez se pudesse dizer que o pequeno funcionário kafkiano desse não processo opera cada vez mais como planejador financeiro, gerente contábil e cobrador de uma organização que adota práticas análogas às de um autêntico racketeer, no caso, um racketeering de Estado.

Assim é que suspensão de direitos, apropriação econômica direta e governo das condutas se cruzam no processo de conversão de funções jurisdicionais em oportunidades de incremento e extração forçada de recursos. Para voltar ao ponto reiterado ao longo deste trabalho, trata-se de um cruzamento bem característico de certa experiência social marcada pela articulação entre autoritarismo e eficiência, em que a governamentalização neoliberal do Estado não vai sem o acionamento de mecanismos coercitivos de imposição da conduta. A respeito, reafirme-se, na esteira das observações de Horkheimer, que o racket se estabelece frequentemente pela apropriação privada de "funções socialmente necessárias" e que o autor das situações de ameaça é

\footnotetext{
14 Em Ferguson, o departamento de polícia realiza reuniões periódicas para divulgação da performance comparativa dos agentes tendo em vista possibilidades de incrementar o número de autuações por oficial. No âmbito judicial, o valor das multas é estipulado sem consideração da gravidade da ofensa nem tampouco da capacidade financeira do acusado.
} 
o próprio beneficiário da oferta forçada de proteção, a um tempo produtor da desordem e garante imposto da ordem $;{ }^{15}$ e, mais uma vez na companhia de Misse, reafirme-se ainda que os esquemas racketeering frequentemente se constituem pela oferta de uma "mercadoria muito especial, constituída por relações de força e poder ou extraída simplesmente da autoridade pública, uma fração privatizada e mercantilizada da soberania do Estado" (2007, p. 142, grifo nosso).

Do ponto de vista da especificação do conceito de racionalidade neoliberal, nossa experiência histórica marcada pela acumulação social da violência e pela circulação das mercadorias políticas se constituiria como revelador analítico dos contornos precisos pelos quais a disseminação de uma grade de inteligibilidade econômica pelas mais diferentes esferas sociais demanda o recurso crescente a práticas soberanas de disposição da vida e suspensão do direito.

Ao mesmo tempo que encerra traços históricos distintivos, a articulação truncada entre gestão autoritária e gestão eficiente do crime e da violência - constitutiva da racionalidade neoliberal - não deixa de configurar ao seu modo a face contemporânea que a razão instrumental vai assumindo pela imposição indiferenciada do cálculo econômico a diferentes esferas da sociedade e pela inversão entre meios e fins que a busca cega da eficiência solicita.

\section{Agradecimentos}

$\mathrm{O}$ autor gostaria de registrar seus agradecimentos à Fapesp pelo financiamento da pesquisa que resultou neste artigo (Processo 2014/26812-4) e aos pareceristas de Lua Nova pelas críticas e comentários feitos a uma versão preliminar do trabalho.

\footnotetext{
${ }_{15}$ A expressão "funções socialmente necessárias" aparece em Stirk, 2005, p. 37, ao comentar a teoria do racket esboçada por Horkheimer (minha ênfase); sobre a relação entre ordem e desordem como definidora de práticas racketeering, ver ainda Bröckling (2014).
} 


\section{Laurindo Dias Minhoto}

é professor do Departamento de Sociologia da Universidade de São Paulo (USP), integrante do coletivo de pesquisa Carceral Studies Working Group do Center for the Study of Law \& Society (CSLS), University of California, Berkeley (EUA) e líder do grupo de pesquisa Teoria dos Sistemas e Crítica Social $(\mathrm{CNPq})$.

\section{Bibliografia}

BALKO, Radley. 2013. Rise of the warrior cop: the militarization of America's police forces. New York: PublicAffairs.

BECKETT, Katherine; HARRIS, Alexes. 2011. On cash and conviction: monetary sanctions as misguided policy. Criminology E Public Policy, v. 10, n. 3, pp. 509-537.

BECKETT, Katherine; HERBERT, Steve. 2008. Dealing with disorder: social control in the post-industrial city. Theoretical Criminology, v. 12, n. 1, pp. 5-30.

BECKETT, Katherine; HERBERT, Steve. 2010. Penal boundaries: banishment and the expansion of punishment. Law $\mathcal{E}$ Social Inquiry, v. 35, n. 1, pp. 1-38.

BECKETT, Katherine; WESTERN, Bruce. 2001. Governing social marginality: welfare, incarceration, and the transformation of state policy. Punishment E Society, v. 3, n. 1, pp. 43-59.

BRÖCKLING, Ulrich. 2014. Rackets and racketeers: a sociological approach to "men of disorder". Paper apresentado no International Workshop Men of Disorder: Masculinity, Violence and Urban Networks in the Modern Middle East and Central Asia, Freiburg, 24 de abril. Disponível em: https://bit.ly/3c7hdSr. Acesso em: 25 fev. 2020.

BUTLER, Judith. 2004. Precarious life. London: Verso.

CAVADINO, Michael; DIGNAN, James. 2007. The penal system: an introduction. London: SAGE.

COLLIER, Stephen J. 2011. Topologias de poder: a análise de Foucault sobre o governo político para além da "governamentalidade". Revista Brasileira de Ciência Política, v. 5, pp. 245-284.

CROUCH, Colin. 2011. The strange non-death of neoliberalism. Cambridge: Polity.

DEAN, Mitchell. 2010. Governmentality: power and rule in modern society. London: SAGE.

FEELEY, Malcolm M.; SIMON, Jonathan. 1992. The new penology: notes on the emerging strategy of corrections and its implications. Criminology, v. 30, n. 4, pp. 449-474. 
FOUCAULT, Michel. 2003. Society must be defended: lectures at the Collège de France (1975-1976). London: Allen Lane.

FOUCAULT, Michel. 2007. Security, territory, population: lectures at the Collège de France (1977-1978). New York: Palgrave Macmillan.

GARLAND, David. 2001a. The meaning of mass imprisonment. In: GARLAND, David (ed.). Mass imprisonment: social causes and consequences. London: SAGE. pp. 1-3.

GARLAND, David. 2001b. The culture of control. Oxford: Oxford University Press.

GRAHAM, Stephen. 2012. Foucault's boomerang: the new military urbanism. Development Dialogue, v. 58, pp. 37-46.

GRANTER, Edward. 2017. Strictly business: critical theory and the society of rackets. Competition E Change, v. 21, n. 2, pp. 94-113.

Hallsworth, Simon. 2002. The case for a postmodern penality. Theoretical Criminology, v. 6, n. 2, pp. 145-163.

HARCOURT, Bernard E. 2001. Illusion of order: the false promise of broken windows policing. Cambridge: Harvard University Press.

HARCOURT, Bernard E. 2018. The counterrevolution: how our government went to war against its own citizens. New York: Basic Books.

HARRIS, Alexes; EVANS, Heather; BECKETT, Katherine. 2010. Drawing blood from stones: legal debt and social inequality in the contemporary United States. American Journal of Sociology, v. 115, n. 6, pp. 1753-1799.

HORKHEIMER, Max. 2016. On the sociology of class relations. Nonsite, n. 18. Disponível em: https://bit.ly/2uuAP1P. Acesso em: 1 set. 2018.

MINHOTO, Laurindo Dias. 2011. Excesso e racionalização na penalidade contemporânea e expertise nacional. In: VIEIRA, Oscar Vilhena; DIMOULIS, Dimitri (org.). Estado de direito e o desafio do desenvolvimento. São Paulo: Saraiva. pp. 381-400.

MINHOTO, Laurindo Dias. 2014. Nota crítica sobre a teoria dos sistemas, o neoliberalismo e o direito à cidade. Revista Direito e Práxis, v. 5, pp. 462-474.

MINHOTO, Laurindo Dias. 2015. Foucault e o ponto cego na análise da guinada punitiva contemporânea. Lua Nova, n. 95, pp. 289-311.

MISSE, Michel. 2007. Mercados ilegais, redes de proteção e organização local do crime no Rio de Janeiro. Revista de Estudos Avançados, v. 21, n. 61, pp. 139-157.

MISSE, Michel. 2008. Sobre a acumulação social da violência no Rio de Janeiro. Civitas, v. 8, n. 3, pp 371-385.

MISSE, Michel. 2018. Violence, criminal subjection and political merchandise in Brazil: an overview from Rio. International Journal of Criminology and Sociology, v. 7, pp. 135-148. 
O'MALLEY, Pat. 2009. Neoliberalism and risk in criminology. In: ANTHONY, Thalia; CUNNEEN, Chris (ed.). The critical criminology companion. Sidney: Federation. pp. 55-67. Disponível em: https:/ /bit.ly/2SXVC7f. Acesso em: 25 fev. 2020.

PRATT, John. 2011. Norbert Elias, the civilizing process and penal development in modern society. The Sociological Review, v. 59, n. 1, pp. 220-240.

RADZINOWICZ, Leon. 1999. Adventures in criminology. New York: Routledge.

REGATIERI, Ricardo Pagliuso. 2015. Do capitalismo monopolista ao processo civilizatório: a crítica da dominação nos debates no Instituto de Pesquisa Social no início da década de 1940 e na elaboração da Dialética do Esclarecimento. Tese de Doutorado em Sociologia. São Paulo: USP.

SIMON, Jonathan. 2007. Governing through crime: how the war on crime transformed American democracy and created a culture of fear. London: Oxford University Press.

SIMON, Jonathan. 2013. Punishment and the political technologies of the body. In: SIMON, Jonathan; SPARKS, Richard (ed.). The SAGE handbook of punishment and society. London: Sage. pp. 60-89.

190 SOZZO, Maximo. 2001. "Traduttore Traditore": traducción, importación cultural e historia del presente de la criminología en América Latina. Cuadernos de Doctrina e Jurisprudencia Penal, v. 7, n. 13, pp. 353-431.

SOZZO, Maximo. 2014. Beyond Neoliberalism? A critical reading of the uses of this concept to think about contemporary transformations of penality. Conferência anual apresentada no European Group for the Study of Deviance and Social Control, Liverpool. Disponível em: https://bit.ly/37W8Aqn. Acesso em: 25 fev. 2020.

SOZZO, Maximo. 2016. Postneoliberalismo y penalidad en América del Sur: a modo de introducción. In: SOZZO, Maximo (comp.). Postneoliberalismo y penalidad en América del Sur. Buenos Aires: Clacso. pp. 9-28.

STIRK, Peter M. R. 2005. Critical theory, politics, and society: an introduction. London: Continum.

TELLES, Vera. 2013. Jogos de poder nas dobras do legal e do ilegal: anotações de um percurso de pesquisa. Serviço Social E゚ Sociedade, v. 115, pp. 443-461.

UNITED STATES OF AMERICA. United States Department of Justice. 2015. Investigation of the Ferguson Police Department. Washington, DC: United States Department of Justice. Disponível em: https://bit. ly/32t5v0c. Acesso em: 2 out. 2018. 
VITALE, Alex S. 2014. How to end militarized policing. The Nation, New York. Disponível em: https://bit.ly/2SZAyxt. Acesso em: 25 fev. 2020.

WACQUANT, Loïc. 2007. Rumo à militarização da marginalização urbana. Discursos Sediciosos, n. 15/16, pp. 203-220.

WACQUANT, Loïc. 2010. Crafting the neoliberal state: workfare, prisonfare, and social insecurity. Sociological Forum, n. 25, pp. 197-220.

WESTERN, Bruce. 2017. Alexes Harris, "A Pound of Flesh: Monetary Sanctions as Punishment for the Poor". Theoretical Criminology, v. 21, n. 2, pp. 247-252. 


\section{ENCARCERAMENTO EM MASSA, RACKETEERING DE ESTADO E RACIONALIDADE NEOLIBERAL}

\section{LAURINDO DIAS MINHOTO}

Resumo: Argumenta-se que a análise da natureza dos regimes punitivos de países do sul global constitui plataforma privilegiada de observação do fenômeno contemporâneo do encarceramento em massa. Não apenas para iluminar o caráter articulado das tecnologias de poder e dos efeitos bumerangue que aproximam padrões de controle da conduta e governo das populações em diferentes formações sociais do capitalismo global, mas, sobretudo, para revelar a própria direção mais geral desses processos. Dessa perspectiva, analisar a experiência brasileira poderia contribuir para especificar o conceito de racionalidade neoliberal e o modo como ele configura o encarceramento em massa, na medida em que a articulação truncada entre gestão autoritária e eficiente do crime e da violência que está na base de processos de criação e reprodução de mercados ilegais e informais no país, com a consequente saturação econômica de sentido de diferentes esferas sociais, anda de par com a adoção de práticas análogas às dos rackets e com a apropriação violenta de recursos econômicos e meios de poder.

Palavras-chave: Encarceramento em Massa; Tecnologias de Poder; Racketeering; Racionalidade Neoliberal; Sociologia da Punição.

\section{MASS INCARCERATION, STATE RACKETEERING AND NEOLIBERAL RATIONALITY}

Abstract: The nature of punitive regimes in southern countries is argued to serve mainly as a means to observe the contemporary phenomenon of mass incarceration, not only to clarify the articulated nature of the technologies of power and the boomerang effects that bring together patterns of the control of conduct and government of 
populations in global capitalism but, above all, to reveal the more general direction of these processes. Thus, analysis of the Brazilian experience could contribute to specify the concept of neoliberal rationality and the way in which it constitutes mass incarceration, insofar as the truncated articulation between authoritarian and efficient management of crime and violence — which forms the basis of processes of creation and reproduction of illegal and informal markets in the country-and the consequent economic saturation of meaning of different social spheres go hand in hand with the adoption of racket-like practices and the violent appropriation of economic resources and means of power.

Keywords: Mass Incarceration; Technologies of Power; Racketeering; Neoliberal Rationality; Sociology of Punishment.

Recebido: 11/02/2019 Aprovado: 25/03/2020 